\title{
MITO E HISTÓRIA ENCENADOS NO “NAVIO NEGREIRO"
}

\author{
MYTH AND HISTORY EXHIBITED IN 'NAVIO \\ NEGREIRO”
}

Bárbara Del Rio Araújo ${ }^{1}$

RESUMO: Este trabalho visa ao estudo do poema "O Navio Negreiro" de Castro Alves, para além do enfoque histórico e ideológico que comumente lhe é atribuído no âmbito da crítica literária. Embora seja muito elucidado o aspecto histórico-social de sua composição, o poema pode apresentar também aspectos da mitologia cristã como elemento estruturador, propiciando um diálogo entre a Literatura, História e Mitologia na sua formação lírica. Busca-se, pois contemplar a relação dessas instâncias.

Palavras-chave: "Navio Negreiro"; mitologia cristã; história.

ABSTRACT: This paper aims to study the poem "O Navio Negreiro", by Castro Alves, forward the history and ideological focus that uses to be conferred on it in the literary critic scope. Although it is commonly pointed the history and social aspects of its composition, the poem can also show Christian Mythology aspects as a builder element, propitiating a dialogue among Literature, History and Mythology in its lyric formation. Thereby, we look for contemplating the relations among these elements.

Keywords: "Navio Negreiro"; christian mythology; history.

\section{INTRODUÇÃO}

A crítica literária por muitas vezes se serviu de critérios históricos para reconhecer a importância das obras literárias. De modo frequente, o desejo de historicizar o objeto fez com que esses fossem validados pelos fatos que apresentavam, pela capacidade em representar um determinado período, de maneira que o critério estético, artístico, fosse parcial ou totalmente sobreposto. Castro Alves e sua obra constituem um desses exemplos, pois fora destacado na tradição canônica literária devido às ações de republicanismo, e acima de tudo pela campanha contra a escravatura. O poeta, tido como precursor da fase condoreira do romantismo brasileiro, sempre teve o viés social ressaltado como cerne das suas produções poéticas, o que

\footnotetext{
${ }^{1}$ Mestranda do programa de pós-graduação em estudos literários (POSLIT) da Universidade Federal de Minas Gerais (UFMG). Graduada pela mesma universidade, suas pesquisas e interesses se concentram, sobretudo na área de Literatura Brasileira, especificamente sobre temas como construção estética, forma literária, literatura e sociedade, entre outros. Atualmente desenvolve um estudo sobre a composição estética da obra Canaã (1902), do autor Graça Aranha fomentada pela Coordenação de Aperfeiçoamento de Pessoal de Nível Superior (CAPES).
}

Raído, Dourados, MS, v. 5, n. 10, p. 111-120, jul./dez. 2011. 
relegou a uma posição marginal ou ao quase esquecimento a nobreza de suas líricas amorosas e dramas teatrais.

Tomada como instrumento, a poesia castroalvina teve pela crítica literária o quadro poético, a formulação literária, transferido para o quadro político-histórico, desempenhando uma função ilustrativa e informativa de modo que a forma, a composição estética, fosse suplantada pela representatividade ideológica. Assim como o autor foi denominado "poeta dos escravos" ou o "poeta da liberdade", o poema "O Navio Negreiro: Tragédia no mar" extraído do livro Os escravos também foi, por muitas vezes, apresentado pelo seu aspecto social, possuindo o epíteto de "canto abolicionista".

"O Navio Negreiro: Tragédia no mar", poema apontado pela tradição histórica e literária como um drama épico, cuja temática expõe a piedade pelos cativos na situação descrita a bordo do navio, tem repetitivas vezes seu mérito na sensibilidade ao problema da escravidão e na representação histórica desse período. Embora reconheça sua inspiração libertadora e saiba de sua apropriação dos embates do movimento liberal, já que foi por diversas vezes declamado tomando dimensão pública abolicionista, proponho estudar talvez o mais representativo dos poemas desse período sob outro viés. Proponho um estudo da sua composição a fim de evidenciar que os fatores históricos e sociais são elementos estruturadores da configuração interna do poema assim como a mitologia cristã, propiciando nessa formação lírica uma interação entre a Literatura, a História e Mitologia.

\section{1 "NAVIO NEGREIRO": A COMPREENSÃO DO POEMA PELO SEU DINAMISMO SEMÂNTICO INTERNO}

Observado pela invenção poética da linguagem, o poema "O Navio Negreiro" demonstra um cuidado de elaboração que extrapola a mera adesão sentimental ou o viés puramente social. O crítico Guilherme Merquior, assim como Ivan Cavalcante, associa a importância do aspecto conteudístico do poema, (de reivindicação e denúncia), veemente ressaltado pela tradição literária, ao aparato lírico, ao trabalho com a forma (o vocabulário, a imagística criada). Para ambos os estudiosos, o poema revela, antes de ser erigido a crítica ideológica como um pretexto para um refinado descritivismo, para uma exibição do gosto romântico pelo exótico ou pelo particularismo local, virtuosidades no trato com a linguagem poética e perfeição formal (Cf. MERQUIOR, 1977, p. 134). José Veríssimo (1969) explana que esse cuidado com a forma não se trata simplesmente de uma elaboração métrica, mas da correlação entre palavra e pensamento, a sobriedade da expressão que realça singularmente a composição, além de evidenciar imagens novas, verdadeiras e belas de fato.

Analogamente, Fausto Cunha se baseia nessa proposição estética e analisa os recursos de composição do poema que, segundo o crítico, são responsáveis pela "evasão do Ultra-Romantismo": 
Ao contrário de quase todos os românticos que empenhavam na poesia dita social o espírito e o verso, Castro Alves, só empenhava o espírito. Sua tendência era fugir do interior para os exteriores, do todo para os detalhes, do tema para os acessórios, do ideológico para o descritivo. [...] Nas "Vozes d'África" e no "Navio Negreiro" a cada instante o pensamento histórico, social é soterrado pelo pensamento poético, o fato pela metáfora, o real pelo idealizado. (CUNHA, 1971, p. 41-42).

Fausto Cunha, diferentemente da concepção adotada por Evaristo de Morais, em $A b c$ de Castro Alves (1965), que aposta na obra pelo seu caráter documental e histórico, atenta para a validade da criação, para o valor da arte o qual não se enquadra na ideia de uma aproximação direta ao momento histórico e ao mundo empírico. Para o crítico supracitado, essa referencialidade é "soterrada" pelo poético, ainda que a inspiração coletiva da época pareça ser o legado que o poema em discussão deixou à posteridade, sua importância é secundária diante do particularismo empreendido pela visão do poeta na composição lírica.

Nesse raciocínio, entende-se que a construção artística não é de fato a realidade do período, o que não quer dizer que esta esteja apartada do elemento social ou da história, mas se estabelece que a relação entre essas esferas, não ocorre de forma tão direta a ponto de sugerir a imitação de uma pela outra. A representação da realidade no poema ocorre de forma matizada. A criação poética e sua nítida relação com outros fenômenos, sobretudo os históricos e sociais, são pensadas a partir de uma noção de reciprocidade, fazendo com que a co-relação do campo estético conflua em uma forma orgânica mais complexa.

Theodor Adorno (2003), em suas proposições acerca da relação imanente entre Literatura, Sociedade e História, ressalta que a referência ao social deve conduzir ao fundo da obra de arte e não pra fora dela. Fugindo de ser escopo de teses sociológicas, evitando ser produto puramente das experiências e emoções de um indivíduo, as composições líricas trazem na essência, na forma, o elemento histórico-social. Não é o caso, porém, de discutir o poema como um retrato do período, validado em função do momento da escravidão ou da volição castroalvina pelo abolicionismo, mas entender que esses elementos constituem sua semântica interna.

Antonio Candido, em Literatura e Sociedade, compreende essa articulação entre história, realidade e objeto artístico pelo processo que nomeou de redução estrutural, ou seja, a associação entre o externo, não como causa nem significado, à constituição interna da obra. Nessa perspectiva, a partir da construção narrativa, do modo pelo qual se organiza a linguagem a realidade é plasmada no poema, tornando-se dependente dele, mas nunca sua cópia. A dinâmica da escravidão é, portanto configurada no poema "O Navio Negreiro" como parte constituinte, não somente do aspecto temático, conteudístico, de fundo, mas também sob aspecto da forma, na integridade e dinamicidade das estrofes e versos.

Alfredo Bosi consegue definir bem a representatividade da poesia de Castro Alves, para além do ponto de vista historicista: 
[...] Tocar com a mão a corrente da História parece uma experiência acessível a qualquer leitor dos poemas sociais de Castro Alves [...] "Vozes d'Àfrica" e " O Navio Negreiro" foram amados e compreendidos como falas de rebeldia, e com certeza uma abordagem de receptação confirmam essa leitura. No entanto, o uso de gerações sucessivas de admiradores esta longe de exaurir os seus significados. Em alguns casos uma só decodificação, sempre reiterada deixa na sobra a verdade de outras conotações igualmente válidas e capazes de dialetizar o sentido uniforme que o consenso estabeleceu. (BOSI, 2005, p. 201).

A análise que se segue busca, enfim, tratar da composição estética do poema a fim de perceber que o aspecto histórico, o imbui não somente como tema ou assunto, mas, sobretudo, como um elemento estruturador, da mesma maneira com que a mitologia cristã, presente no Gênesis bíblico, integra-o em forma e conteúdo.

\section{A FANTASIA POÉTICA: OS ELEMENTOS HISTÓRICOS E MÍTICOS ATUANTES NA COMPOSIÇÃO LÍRICA}

“O Navio Negreiro: Tragédia no mar" traz elementos da história estilizada no tratamento poético da angustiosa cena do cativeiro e do trânsito das naus no transporte dos escravos. O trabalho com a linguagem faz com que as cenas sejam construídas de forma eloquente a fim de comover o espectador. Castro Alves pinta, através de um jogo de perspectivas, o brigue voador no mar e o adentra focalizando em especial a cena do tombadilho. A história é acessada e recomposta por meio da linguagem. As imagens do escravo e do navio negreiro são revitalizadas e reconstruídas servindo a configuração interna do poema. Todo aparato emocional, ideológico histórico vertem e são apresentados nos domínios da invenção poética. O crítico Fausto Cunha atribui ao poeta a capacidade suprema da descrição que predominava sobre os sentidos e adesão sentimental. Assim, lhe atribui a capacidade de ser um anacronista, pois não preocupado com validade histórica de sua obra, com a serviência a representação de um período, consegue no literário criar a engrenagem da realidade:

Somente um artista absolutamente desinteressado da validade histórica de sua obra poderia construir um dos seus mais arrojados e mais valiosos trabalhos sobre um anacronismo; somente um descritivo como Castro Alves se empolgaria, como fez no Navio negreiro, por uma imagem altamente plástica de Heine - a dos negros chicoteados num tombadilho - sendo que o tráfico de escravos havia sido extinto dezoito anos antes, quando ele mal tinha nascido. (CUNHA, 1971, p. 42).

É preciso, pois, deixar claro que o aparato histórico não incute no poema como cópia fiel e exata do plano real, mas uma reconstrução elaborada pelo uso da expressão. Embora não conte com personagens em ação dialógica, a composição 
poética sugere dramaticidade por meio de figuras alegóricas compondo o estético e misturando a esfera subjetiva às referências ao plano real e histórico. Os trechos que seguem focalizam imagens objetivas do plano histórico revelando que a realidade figurada não se apresenta como algo estático desligado do movimento real da história, mas, pelo contrário compõe o arranjo de forma poética (SCHWARZ, 2006, p. 52).

'Stamos em pleno mar. . abrindo as velas

Ao quente arfar das virações marinhas,

Veleiro brigue corre à flor dos mares,

Como roçam na vaga as andorinhas...

Donde vem? onde vae? Das náus errantes

Quem sabe o rumo se é tão grande o espaço?

Neste sahara os corseis o pó levantam,

Galopam, voam, mas não deixam traço...

(ALVES, 1972, p. 170).

A história, as grandes navegações, a exploração dos oceanos compõem a matéria da parte do poema citado. O eu lírico descreve o objeto observado, questiona a sua origem ao mesmo tempo impressiona-se e com a velocidade que este atravessa as águas. Utilizando de imagens alegóricas, o sujeito expresso reconstrói fatos históricos, que têm como espaço o mar. Entre cruzadas do decadentismo italiano, a "batalha do mito", os marinheiros Nelson e Albourquir, os fatos históricos seguem compondo a forma poética sem o pragmatismo de justificar ou explicar a cena descrita; ao contrário, é insumo a sequência imagística interna que o poeta estabelece:

O Inglez - marinheiro frio, Que ao nascer no mar se achou, (Porque a Inglaterra é um navio, Que Deus na Mancha ancorou), Rijo entoa pátrias glórias, Lembrando, orgulhoso, histórias

De Nelson e de Abouquir...

O Francez - predestinado -

Canta os louros do passado

E os loureiros do porvir!

(ALVES, 1972, p. 174).

A mitologia logo integra o imaginário dos mares assim como aparece na matéria poética. O herói da Odisséia, assim como o escultor que reedificou Acrópole, estão presentes na criação poética caracterizando os nautas dos barcos de origem diversas:

Os marinheiros Hellenos,

Que a vaga ionia creou,

Bellos piratas morenos

Do mar que Ulisses cortou, Homens que Phyidias talhara, Vão cantando em noite clara Versos que Homero gemeu ... 
Nautas de todas as plagas, Vós sabeis achar nas vagas As melodias do céu! ...

(ALVES, 1972, p. 177).

Em um jogo de perspectivas, ressaltando os ângulos e distâncias, como analisa o crítico Antonio Candido (Cf. CANDIDO, 2004, p. 55), o poeta, observador, narra descritivamente das alturas o navio ao mesmo tempo em que ouve cantigas ressoantes dele. Esse observador mergulha pela ajuda da ave condoreira no interior do objeto descrito, desvencilhando-o. A excitação e beleza, outrora contempladas do exterior, não se mantêm na descrição interna da nau:

Desce do espaço immenso, ó águia do oceano!

Desce mais ... inda mais... não póde olhar humano

Como o teu mergulhar no brigue voador!

Mas que vejo eu ahi... Que quadro d'amarguras!

É canto funeral! ... Que tétricas figuras!...

Que cena infame e vil... Meu Deus! Meu Deus! Meu Deus! Que horror!

(ALVES, 1972, p. 177).

Diante do paralelo de beleza e horror encenados imageticamente, o crítico já referido, Candido, interpreta o poema por uma espécie de lei fundamental, que o constitui: o jogo de extremos. Para ele, os recursos da fatura são utilizados a cruzarem e se repelirem, criando grandes contrastes. Assim, a harmoniosa beleza externa do navio, o mar, cantados nas primeiras estrofes, é contraposta a cena interna de crueldade, a tragédia do tombadilho, mostra de iniquilidade da escravidão que interrompia a vida africana.

Era um sonho dantesco... o tombadilho

Que das luzernas avermelha o brilho.

Em sangue a se banhar.

Tinir de ferros... estalar de açoite...

Legiões de homens negros como a noite,

Horrendos a dançar...

Negras mulheres, suspendendo às tetas

Magras creanças, cujas boccas pretas

Rega o sangue das mães:

Outras, moças, mas núas e espantadas,

No turbilhão de espectros arrastadas,

Em ânsia e mágoa vãs!

(ALVES, 1972, p. 178).

Sob diferentes ângulos o interior do navio é descrito. O horror da cena dos escravos obrigados a dançar enquanto os marinheiros os açoitam, as crianças famintas penduradas aos seios das mães trazem à tona o tema histórico da escravidão que é mencionado integrando o poema de forma particularizada, como descreve José Paulo Pães: 
Em vez de focalizar a escravidão em termos gerais, ideológicos, como tanta má poesia abolicionista antes e depois dele, preferiu mais das vezes pintar o escravo em uma circunstância particular, dramaticamente significativa. Pintou-o no tombadilho de "O Navio Negreiro" a dançar grotescamente sob o estalo dos chicotes. (PAES, 1995, p. 71).

O crítico ainda explicita que Castro Alves soube ressemantizar a figura do escravo assim como o fez para o tema da escravidão empreendendo de modo renovado o conteúdo e sua representação formal de modo a atribuir altura e dignidade a poesia social. Alfredo Bosi, na análise do poema "Vozes d'Àfrica", mostrou que o tema do cativeiro é tratado de modo diferenciado, elaborado por elementos históricos e míticos. De maneira semelhante, o poema "O Navio Negreiro: Tragédia no mar" incorpora tanto aspectos históricos sociais quanto elementos da mitologia cristã a compor sua a semântica interna, ou seja, a formação do poético se dá na medida em que acontecimentos históricos e míticos são operacionalizados, recriados no âmbito literário.

O aspecto mítico, especificamente, é expresso quando o poeta povoa o imaginário lendário acerca da origem (quem são e de onde vem) dos negros que dançam e habitam o interior do navio:

Quem são estes desgraçados

Que não encontram em vós

Mais que o rir calmo da turba

Que excita a fúria do algoz?

Quem são? Se a estrella se cala,

Se a vaga opressa resvala

Como um cúmplice fugaz,

Perante a noite confusa...

Dize-o tu, severa Musa,

Musa libérrima, audaz!...

(ALVES, 1972, p. 180).

A resposta da pergunta sobre a origem desse povo "Quem são estes desgraçados..." vem logo na estrofe seguinte, a qual articula junto à esfera mítica do continente africano, o mito cristão relatado no livro bíblico do Gênesis:

São os filhos do deserto,

Onde a terra esposa a luz.

Onde vive em campo aberto

A tribo dos homens nús...

São os guerreiros ousados

Que com os tigres mosqueados

Combatem na solidão.

Hontem simples, fortes, bravos...

Hoje míseros escravos,

Sem luz, sem ar, sem razão. . .

São mulheres desgraçadas,

Como Agar o foi também. 


\begin{abstract}
Que sedentas, alquebradas, De longe... bem longe vêm... Trazendo com tíbios passos, Filhos e algemas nos braços, N'alma - lágrimas e fel... Como Agar sofrendo tanto, Que nem o leite de pranto Têm que dar para Ismael.
\end{abstract}

(ALVES, 1972, p. 180-181).

O sofrimento das mães negras tem como referência direta a narração da escritura bíblica sobre a escrava egípcia Agar, concedida a Abraão para dar-lhe um filho, já que sua esposa, Sara, era impossibilitada de tornar-se mãe. Agraciada pela fertilidade, Sara dá à luz a Isaac e a escrava Agar junto com seu filho Ismael é condenada a vagar no deserto:

Sara, porém tendo visto o filho de Agar Egípcia, que escarnecia de seu filho Isaac disse para Abraão: Expulsa essa escrava e seu filho, porque o filho da escrava não há de ser herdeiro com o meu filho Isaac. Este falar foi duro para Abraão por causa do seu filho (Ismael). Deus porém disse-lhe: não te pareça áspero tratar assim o menino e a tua escrava. Atende Sara em tudo o que ela te disser, porque de Isaac sairá a descendências que há de ter o teu nome. Mas também do filho da escrava farei um grande povo, por ser teu sangue. (BÍBLIA SAGRADA, 21 9-13).

O efeito de anátema entre a situação dessas mulheres faz com que elementos da história e da mitologia se misturem na facção poética. O poeta trabalha com materiais míticos, históricos e literários que apesar da sua aparência dispersiva acabam incidindo todos no escândalo milenar da escravidão africana (BOSI, 2005, p. 260). A matéria poética, nesse sentido, assemelha-se à matéria épica resultada da ação criativa em fundir referentes míticos e históricos potencializando a significado do poético. Imagens e símbolos são articulados fazendo conviver pelo processo criativo tempo e espaço diversos, além de remover as fronteiras das áreas de conhecimento como História, a Literatura e a Mitologia.

Nas estrofes que seguem o poema, apropriando-se da origem mítica do povo africano e da situação em que se encontram no tombadilho, passado e presente se relacionam de modo a criar mais imagens contrastantes, antitéticas a enfatizar a oposição elementar no poema Liberdade versus Escravidão:

Hontem a Serra Leôa,

A guerra, a caça ao leão,

O somno dormido à toa

Sob as tendas d'amplidão!

Hoje... o porão negro, fundo,

Infecto, apertado, immundo,

Tendo a peste por jaguar...

E o somno sempre cortado 
Pelo arranco de um finado, E o baque de um corpo ao mar...

Hontem plena liberdade, A vontade por poder... Hoje... Cum'lo de maldade, Nem são livres p'ra morrer. . Prende-os a mesma corrente - Férrea, lúgubre serpente Nas roscas da escravidão.

E assim zombando da morte, Dança a lúgubre cohorte Ao som do açoute... Irrisão!... (ALVES, 1972, p. 180).

O movimento livre do guerreiro vs restrição imposta pelas cadeias; espaço aberto que era abrigo $v$ s porão apertado são oposições deflagradas que não se unificam. O poeta povoa plasticamente o seu universo com uma variedade de coisas e situações convergindo magistralmente para o objetivo de intenção ética e social (CANDIDO, 2004, p. 58). Desta maneira, há prefigurado no poema um trabalho de linguagem por detrás do conteúdo social exaltado. $\mathrm{O}$ tom declamatório, a eloquência, sugerindo certa adesão ao palco e cenário dos acontecimentos delatados, que saltam aos olhos na leitura, tudo é fruto de um efeito estético, da maneira com que a matéria poética é estruturada.

A dimensão histórica e as referências míticas reelaboradas na configuração temática e formal da instância poética fazem ampliar sua significação simbólica, na medida em que o artista consegue captar no seio da cultura as imagens desses diversos discursos, traspassando suas fronteiras, articulando-os ao plano literário, fundindo na composição o tempo e espaço que os dividem. A temática da escravidão é, portanto, redimensionada, recriada por uma matéria épica, cujo discurso tem sua especificidade na dupla instância da enunciação mítica e historiográfica. Na obra Historia da Epopéia Brasileira, os autores Anazildo Vasconcelos da Silva e Christina Ramalho, tomando por base os estudos aristotélicos, buscam evidenciar a continuidade do discurso épico na ação criativa e na configuração temática da ideia, o que nos permite apropriar do poema em análise pela realização literária de um épos - "articulação de referenciais históricos e simbólicos associados em um processo de formação cultural de um povo" (SILVA; RAMALHO, 2007, p. 53).

Assim, é na facção poética composicional que o autor consegue articular elementos da historia e da mitologia, desenvolvendo a matéria épica pela sanção do literário. Tão importante quanto às afeições panfletárias da abolição, da luta contra o sistema escravista, está a organização interna do poema que o mantém vivo, mesmo quando extinto da História Brasileira o tráfico negreiro. Os dizeres de Fausto Cunha mostram bem que a relevância do poema na historiografia não se dá pela razão empenhada à causa escravista, mas pela maneira com que na forma literária os elementos composicionais são articulados: 
Ele (Castro Alves) compreendeu ou pelo menos sentiu, o que nenhum contemporâneo (exceto Varela) parecia compreender ou sentir: o que confere a uma obra de arte poder sobre o tempo não é a causa que ela defende, ou o sentido de que se imbui. é a sua qualidade. A utilização extra-literária de uma obra que sobrevive são os frutos ou percalços, da sua permanência. (CUNHA, 1971, p. 42).

\section{REFERÊNCIAS}

ADORNO, Theodor. Palestra sobre lírica e sociedade. In: Notas de literatura I. São Paulo: Duas Cidades/Edições 34, 2003.

ALVES, Castro. Os escravos. São Paulo: Martins, 1972.

AMADO, Jorge. ABC de Castro Alves. 10. Ed. São Paulo: Martins, 1965.

BIBLIA. Português. Bíblia Sagrada. Tradução Pe. Matos Soares. 11. Ed. São Paulo: Edições Paulinas, 1982.

CANDIDO, Antonio. Recortes. Rio de Janeiro: Ouro sobre Azul, 2004.

Literatura e sociedade. 9. ed. Rio de Janeiro: Ouro sobre Azul, 2006.

CUNHA, Fausto. O romantismo no Brasil: de Castro Alves a Souzandrade. Rio de Janeiro: Paz e Terra, 1971.

BOSI, Alfredo. Sob o signo de Cam. In: . Dialética da colonização. São Paulo: Cia das Letras, 2005.

MERQUIOR, Jose Guilherme. De Anchieta a Euclides: breve historia da literatura Brasileira. Rio de Janeiro: José Olympio, 1977.

PAES, Jose Paulo. O condor pragmático. In: Transleituras: ensaios de interpretação literária. São Paulo: Ática, 1995.

SILVA, A. V.; RAMALHO, C. História da epopéia brasileira: teoria, crítica e percurso. Rio de Janeiro: Garamond, 2007.

SCHWARZ, Roberto. O pai de família e outros estudos. 2. ed. São Paulo: Companhia das Letras, 2006.

VERÍSSIMO, José. História da literatura brasileira: Bento Teixeira 1601 a Machado de Assis 1908. Rio de Janeiro: José Olympio, 1969. 